\title{
Expanded Regulatory T Cells Induce Alternatively Activated Monocytes With a Reduced Capacity to Expand T Helper-17 Cells
}

\author{
Marco Romano', Giorgia Fanelli', Nicole Tan ${ }^{1}$, Estefania Nova-Lamperti ${ }^{1,2}$, \\ Reuben McGregor ${ }^{1}$, Robert I. Lechler ${ }^{1}$, Giovanna Lombardi ${ }^{1 \dagger}$ and Cristiano Scottà ${ }^{1 * \dagger}$ \\ 'Immunoregulation Laboratory, MRC Centre for Transplantation, School of Immunology \& Microbial Sciences, King's College \\ London, London, United Kingdom, ${ }^{2}$ Molecular and Translational Immunology Laboratory, Department of Clinical \\ Biochemistry and Immunology, Faculty of Pharmacy, University of Concepcion, Concepcion, Chile
}

OPEN ACCESS

Edited by:

Djordje Miljkovic,

Institute for Biological Research

Sinisa Stankovic, Serbia

Reviewed by:

Femke Broere,

Utrecht University, Netherlands

Silvia Gregori,

Istituto San Raffaele Telethon per la

Terapia Genica (SR-Tiget), Italy

${ }^{*}$ Correspondence:

Cristiano Scottà

cristiano.scotta@kcl.ac.uk

tThese authors have contributed equally to this work.

Specialty section: This article was submitted to Immunological Tolerance and Regulation,

a section of the journal

Frontiers in Immunology

Received: 29 April 2018

Accepted: 02 July 2018

Published: 20 July 2018

Citation:

Romano M, Fanelli G, Tan N,

Nova-Lamperti E, McGregor R, Lechler RI, Lombardi G and Scottà C (2018) Expanded Regulatory T Cells

Induce Alternatively Activated Monocytes With a Reduced Capacity to Expand T Helper-17 Cells.

Front. Immunol. 9:1625. doi: 10.3389/fimmu.2018.01625
Regulatory T cells (Tregs) are essential in maintaining peripheral immunological tolerance by modulating several subsets of the immune system including monocytes. Under inflammatory conditions, monocytes migrate into the tissues, where they differentiate into dendritic cells or tissue-resident macrophages. As a result of their contextdependent plasticity, monocytes have been implicated in the development/progression of graft-vs-host disease (GvHD), autoimmune diseases and allograft rejection. In the last decade, Tregs have been exploited for their use in cell therapy with the aim to induce tolerance after solid organ transplantation and for the treatment of autoimmune diseases and GvHD. To date, safety and feasibility of Treg infusion has been demonstrated; however, many questions of how these cells induce tolerance have been raised and need to be answered. As monocytes constitute the major cellular component in inflamed tissues, we have developed an in vitro model to test how Tregs modulate their phenotype and function. We demonstrated that expanded Tregs can drive monocytes toward an alternatively activated state more efficiently than freshly isolated Tregs. The effect of expanded Tregs on monocytes led to a reduced production of pro-inflammatory cytokines (IL-6 and tumor necrosis factor- $\alpha$ ) and NF-kB activation. Furthermore, monocytes co-cultured with expanded Tregs downregulated the expression of costimulatory and $\mathrm{MHC}$-class II molecules with a concomitant upregulation of $\mathrm{M} 2$ macrophage specific markers, CD206, heme oxygenase-1, and increased interleukin-10 production. Importantly, monocytes co-cultured with expanded Tregs showed a reduced capacity to expand IL-17-producing T cells compared with monocyte cultured with freshly isolated Tregs and conventional T cells. The capacity to decrease the expansion of proinflammatory Th-17 was not cytokine mediated but the consequence of their lower expression of the co-stimulatory molecule CD86. Our data suggest that expanded Tregs have the capacity to induce phenotypical and functional changes in monocytes that might be crucial for tolerance induction in transplantation and the prevention/treatment of GvHD and autoimmune diseases.

Keywords: regulatory T cells, immunoregulation, monocytes, alternatively activated macrophages, cell therapy 


\section{INTRODUCTION}

Regulatory $\mathrm{T}$ cells (Tregs) maintain peripheral immunological tolerance by controlling autoreactive $\mathrm{T}$ cells and dampening inflammation (1). These cells represent $5-10 \%$ of all the circulating $\mathrm{CD}^{+} \mathrm{T}$ lymphocytes and constitutively express high level of CD25 and FOXP3 $(2,3)$. Tregs can be broadly divided in two main subpopulations: thymic derived Tregs (4) and peripherally induced Tregs generated by the stimulation of conventional T cells (Tconv) under specific tolerogenic conditions $(5,6)$. Tregs use a plethora of mechanisms to suppress the activation and proliferation of different immune cell subsets (7-9). The release of immunosuppressive cytokines such as interleukin-10 (IL-10) (10) and transforming grow factor- $\beta$ (TGF- $\beta$ ) is essential for Treg function as they can modulate both $\mathrm{T}$ lymphocytes and antigenpresenting cells (APCs) activation (11). IL-10 can downregulate MHC-class II and co-stimulatory molecules on dendritic cells (DCs) $(12,13)$ and, at the same time, reduce the production of IL-6, IL-1 $\beta$ (14), and tumor necrosis factor- $\alpha$ (TNF- $\alpha$ ) (15). However, in inflamed tissues, Tregs interact mainly with monocytes and macrophages. These cells are involved in both innate and adaptive immunity as they have the potential to phagocyte and kill bacteria, produce cytokines, and process/present antigen to lymphocytes (16-18). IL-10, together with TGF- $\beta$, can drive the differentiation of monocytes into M2 type c macrophages (19, 20). Compared with the classical M1 macrophages, these cells express high levels of the hemoglobin-haptoglobin scavenger receptor (CD163) and secrete less pro-inflammatory cytokines (21). Moreover, M2c can promote kidney repair in vivo by deactivating endogenous renal macrophages and by inhibiting CD4 $\mathrm{T}$ cells proliferation (20). Recently, it has been shown that IL-10 released by Tregs during the co-culture with monocytes, induced an upregulation of CD163 and CCL18 followed by reduced release of pro-inflammatory cytokines after LPS stimulation (22). In addition, IL-10 is involved in the control of genes implicated in the clearance of oxidative stress such as heme oxygenase- 1 (HO-1) (23). This enzyme plays an essential role in suppressing immune responses during inflammation (24) autoimmune diseases (25) and allograft rejection (26).

Regulatory $\mathrm{T}$ cells can additionally exert their immunosuppressive function by contact-dependent mechanisms. They are the only T-cells that constitutively express cytotoxic T-lymphocyte antigen-4 (CTLA-4) (27). This molecule binds the same ligands as CD28, CD80, and CD86, thus limiting co-stimulatory signals during T cell activation. CTLA-4 can also downregulate DCs' activity via trans-endocytosis of CD80 and CD86 resulting in diminished co-stimulation and T cell anergy (28).

In addition, the interaction between monocytes and Tregs in vitro induces the upregulation of the mannose scavenger receptor (CD206), a specific marker for M2a macrophages (22).

Current strategies for clinical management of transplant recipients and for the treatment of graft-vs-host disease (GvHD) involve the use of immunosuppressive drugs $(29,30)$. However, they do not fully prevent chronic graft rejection or GvHD and they are linked to morbidity and mortality. For this reason, Tregs have been extensively studied as therapeutic tool for the generation of tolerance in solid organ transplantation and for the treatment of autoimmune disorders and GvHD. Freshly isolated Tregs using Good Manufacturing Practice (GMP) protocols (31) have been infused in phase I clinical trials with no side effects (32-34). However, preclinical studies have also shown that expanded Tregs are more suitable in preventing graft rejection and GvHD than freshly isolated Tregs (35). We have recently developed a clinically applicable protocol for the expansion of human Tregs $(36,37)$ which involves the use of rapamycin and IL-2.

With the aim of better understanding the mechanisms adopted by expanded Tregs in the induction of tolerance, we have settled an in vitro model to study whether Tregs can induce an anti-inflammatory phenotype in monocytes. Monocytes display extreme plasticity in response to signals from the microenvironment and their presence in rejecting allograft tissue is associated with worse graft function and/or survival (38). We hypothesized that the modulation of monocytes by Tregs might be a key mechanism in the induction of tolerance. The data obtained here suggest that expanded human Tregs induce an alternative activation status in monocytes with the potential to support the long-term acceptance of an allograft or to reduce the high inflammatory status which is critical for the progression of GvHD and autoimmune diseases.

\section{MATERIALS AND METHODS}

\section{Cell Isolation and Expansion}

Peripheral blood mononuclear cells (PBMCs) from healthy donors were obtained from anonymized human leukocyte cones supplied by the National Blood Transfusion Service (NHS blood and transplantation, Tooting, London, UK). Human studies were conducted in accordance with the Helsinki Declaration and approved by the Institutional Review Board of Guy's Hospital (Reference 09/H0707/86). Informed consent was obtained from all healthy donors prior to enrollment into the study. PBMCs were isolated by lympholyte $\left(1.077 \mathrm{~g} / \mathrm{cm}^{3}\right)$ gradient stratification (Lymphoprep; Axis-Shield, Norway). Subsequently, highly purified $\mathrm{CD} 4^{+} \mathrm{CD} 25^{+}, \mathrm{CD}^{+} \mathrm{CD} 25^{-}$, CD4 (from HLA-A2 ${ }^{+}$donors), and $\mathrm{CD}_{14}{ }^{+}$cells (from HLA-A2- donors) were isolated using specific immunomagnetic cell isolation Kits (Miltenyi Biotech, Germany) according to the manufacturer's instructions. Freshly isolated T cells were frozen and used when needed. Tregs expansion has been executed as already published by us $(36,39)$. Briefly, cells were cultured in X-Vivo (Lonza, UK) supplemented with $5 \%$ of Human Serum AB Male (BioWest, France) and $100 \mathrm{nM}$ of rapamycin (LC-Laboratories, USA). Cells were then activated with anti-CD3/CD28 beads (ratio bead:cell of 1:1; Invitrogen, UK). IL-2 (1,000 IU/mL; Proleukin, Novartis, UK) was added at day 4 post activation and replenished every 2 days. Cells were re-stimulated every 10-12 days and used after 36 days from the first activation (three rounds of stimulation). Expanded cells were frozen and used when needed.

\section{Flow Cytometry and Cytokine Evaluation}

Freshly isolated Tregs, Tconv, and expanded Tregs have been phenotypically evaluated by flow cytometry using antibodies listed in Table S1 in Supplementary Material. 
After detaching, monocytes were incubated with Human TruStain FcX ${ }^{\mathrm{TM}}$ (Fc Receptor Blocking Solution, BioLegend, USA) for $10 \mathrm{~min}$ and then stained with Live/Dead Yellow (Thermo Fisher Scientific, UK) and extracellular antibodies as listed in Table S1 in Supplementary Material for $30 \mathrm{~min}$ at $4^{\circ} \mathrm{C}$. For intracellular staining, $\mathrm{T}$ cells were activated with PMA/ ionomycin for $5 \mathrm{~h}$ at $37^{\circ} \mathrm{C}$. Cells were then stained with, antiHLA-A2 and CD45RO followed by cell permeabilization and intracellular staining using anti-IL-17 (BL168, BioLegend, USA), anti-IL-4 (8D4-8, Thermo Fisher Scientific, UK), and antiIFN- $\gamma$ (B27, Thermo Fisher Scientific, UK). Permeabilization was performed with the FOXP3/Transcription Factor Staining Buffer Set (Thermo Fisher Scientific, UK) $30 \mathrm{~min} / 4^{\circ} \mathrm{C}$ according to the manufacturer's instructions. Samples were acquired on LSR-Fortessa flow cytometer and files analyzed using Flow Jo 9.7.5 (Tree Star Inc., USA). Supernatants from activated T cells and monocytes were used to detect cytokines production using LEGENDplex Human Th-Cytokine Assay and Human panel 2 Cytokine Assay (BioLegend, USA) according to the manufacturer's instructions. Cytokines were acquired on a FACSCanto II (BD Biosciences, USA). Data analysis was carried out on BioLegend's LEGENDplex Data Analysis Software. TGF- $\beta$ evaluation from monocytes and T cells has been performed using Human TGF- $\beta 1$ Platinum ELISA kit (Thermo Fisher Scientific, UK).

\section{Suppression Assay}

$1 \times 10^{5} \mathrm{CD}^{+} \mathrm{CD}^{2} 5^{-}$(T-effectors) were labeled with CFSE $(2.5 \mu \mathrm{M}$; Molecular Probe, USA) and cultured alone or at different ratios with freshly isolated Tregs, Tconv, and expanded Tregs. Effector $\mathrm{T}$ cells were stimulated with anti-CD3/CD28 beads (Thermo Fisher Scientific, UK) in U-bottom 96-well plates and incubated at $37^{\circ} \mathrm{C}, 5 \% \mathrm{CO}_{2}$ for 5 days. Data were acquired on LSR-Fortessa and analyzed with Flow Jo 9.7.5 software (Tree Star Inc., USA). Suppression of proliferation by Tregs was analyzed as previously described (40).

\section{Monocytes-T Cells Co-Culture}

A co-culture experiment was settled in 48-well plates pre-coated with anti-CD3 monoclonal antibody ( $50 \mathrm{ng} / \mathrm{mL}$; clone UCHT1; BioLegend, USA). $0.5 \times 10^{6}$ monocytes (HLA-A2-) have been co-cultured in presence of $0.25 \times 10^{6} \mathrm{~T}$ cells $\left(\mathrm{HLA}-\mathrm{A} 2^{+}\right.$) for 6 days as detailed in Figure 1. The resultant monocyte populations have been identified as $\mathrm{M}_{25+}$ (monocytes co-cultured with freshly isolated Tregs), $\mathrm{M}_{25-}$ (monocytes co-cultured with Tconv), and $\mathrm{M}_{\exp }$ (monocytes co-cultured with expanded Tregs). Cells were then detached using Accutase (STEMCELL Technologies, UK) and labeled with Live and Dead dying (Thermo Fisher Scientific, UK) and HLA-A2 antibody (Miltenyi, Germany) for sorting, following the gate strategy reported in Figure S1 in Supplementary Material. After sorting, $50 \times 10^{3}$ cells per condition were placed in a new 96-well plate and left at $37^{\circ}$ overnight to ensure a complete adhesion. Adhering cells have been stimulated $24 \mathrm{~h}$ with LPS $(50 \mathrm{ng} / \mathrm{mL})$ and then co-cultured, for other 6 days, with allogeneic CD4 $\mathrm{T}$ cells $\left(10^{5}\right.$ per condition, HLA-A $\left.2^{+}\right)$in the presence of soluble anti-CD3 (clone OKT3 $50 \mathrm{ng} / \mathrm{mL}$; eBioscience). To understand the mechanisms behind the monocytes/CD4 interaction, $\mathrm{M}_{25}$ - have been cultured for 6 days in presence/absence of tocilizumab (100 ng/mL, Roche UK) infliximab (100 ng/mL, Napp Pharmaceutical group, UK) and abatacept (Orencia ${ }^{\circledR}$ Bristol Mayer Squibb, USA). Specifically, to ensure a complete block of TNF- $\alpha$ and the co-stimulation during the co-culture, $\mathrm{M}_{25-}$ have been pre-incubated with Abatacept and Infliximab for at least $1 \mathrm{~h}$; similar to selectively block the IL- 6 receptor only on T cells, CD4 have been pre-incubated with Tocilizumab. Drugs have been replenished after 3 days.

To evaluate the effects of cytokines released by monocytes on $\mathrm{T}$ cell activation, $1 \times 10^{5} \mathrm{CD}^{+} \mathrm{T}$ cells have been activated using anti-CD3/CD28 microbeads (beads to cells ratio 1:4) (Thermo Fisher Scientific, UK) in X-vivo and $\mathrm{M}_{25-}$ conditioned medium.

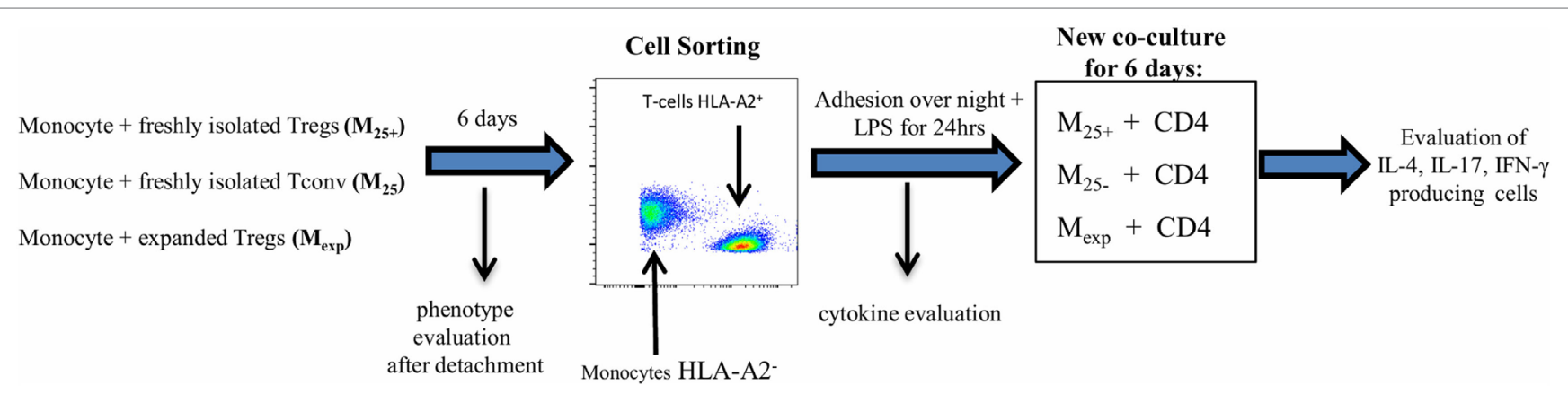

FIGURE 1 | Experimental protocol. Co-culture experiments have been settled in 48-well plates pre-coated with anti-CD3 monoclonal antibody $\left(50\right.$ ng/mL). $0.5 \times 10^{6}$

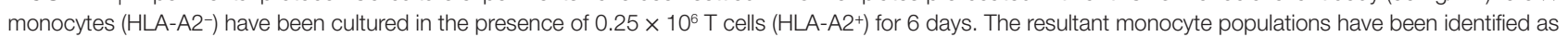
$\mathrm{M}_{25+}$ [monocytes co-cultured with freshly isolated CD4+CD25+ regulatory $T$ cells (Tregs)], $\mathrm{M}_{25-}$ [monocytes co-cultured with freshly isolated CD4+CD25- conventional $\mathrm{T}$ cell (Tconv)], and $\mathrm{M}_{\exp }$ (monocytes co-cultured with expanded Tregs). Cells were then detached and labeled with Live/Dead dying and HLA-A2 antibody for cell sorting following the gate strategy reported in Figure S1 in Supplementary Material. At the same time, the expression of CD86, CD14, CD80 CD40, CD206, CD163, and HLA-DR has been evaluated by flow cytometry. After sorting, $150 \times 10^{5}$ cells have been lysed for WB analysis and $50 \times 10^{3}$ cells per condition were placed in a new 48 -well plate and left at $37^{\circ} \mathrm{C}$ overnight to ensure complete adhesion. Adhering cells have been stimulated with LPS for $24 \mathrm{~h}$ and then co-cultured, for other 6 days, with allogeneic CD4 T cells ( $10^{5}$ per condition, HLA-A2 ${ }^{+}$coming from the same donor of the Tconv/Treg) in presence of soluble anti-CD3 (50 $\left.\mathrm{ng} / \mathrm{mL}\right)$. Intracellular staining to evaluate IL-4, IL-17, and IFN- $\gamma$-producing CD4 T cells has been executed at the end of the co-culture. Supernatant after LPS stimulation ( $50 \mathrm{ng} / \mathrm{mL}$ ) has been used for cytokine evaluation and for the experiment using the $\mathrm{M}_{25-}$ conditioned medium. 


\section{Western Blot Analysis}

Sorted cells were pelleted and lysed with cold RIPA buffer (Thermo Fisher Scientific, UK) containing protease inhibitors $1 \times$ (Calbiochem, Germany). Protein lysates were denaturated by adding $2 \times$ laemmli buffer (Bio-Rad, USA) containing $5 \%$ $\beta$-mercaptoethanol (Sigma-Aldrich, Germany). Protein samples were separated on $10 \%$ SDS polyacrylamide gels and transferred onto polyvinylidene difluoride membranes (Millipore, USA). Membranes were blocked in 5\% non-fat dry milk (Bio-Rad, USA) in PBS $0.1 \%$ Tween-20 for $1 \mathrm{~h}$ at room temperature and incubated with phospho- and total-p65 (Ser536) (both from Cell Signaling Technology, USA), HO-1 (Abcam, UK), and $\beta$-actin (Santa Cruz Biotechnology, USA) antibodies overnight at $4^{\circ} \mathrm{C}$. Proteins were detected with chemiluminescence detection reagents (Bio-Rad, USA) after HRP conjugated secondary antibody (Cell Signaling Technology, USA) incubation using ImageQuant LASS4000 mini (GE Healthcare Life Science, UK) and quantified using Image Studio Lite version 5.2 (LI-COR Biosciences, USA).

\section{Statistical Analysis}

Statistical analyses were performed using Prism Version 7 software (Graph-Pad, USA). Data were expressed as mean \pm SEM where applicable using bar charts. Unpaired $t$-test has been used to evaluate different $T$ cell subsets. One-way ANOVA followed by Tukey test was used for monocytes experiment and all $p$ values were considered significant when $\leq 0.0 .05$. Specifically for $p$ values: ${ }^{*} p<0.05,{ }^{* *} p<0.01$, and ${ }^{* *} p<0.001$.

\section{RESULTS}

\section{Expansion of Tregs Using Rapamycin Increases Their Tolerogenic Functions}

To test the effects of expanded Tregs on monocytes, $\mathrm{CD} 4{ }^{+} \mathrm{CD} 25^{+}$ were isolated and expanded as detailed in Section "Materials and Methods." At the end of the culture, we evaluated the phenotype and function of expanded Tregs compared with freshly isolated Tconv and Tregs.

As shown in Figures 2A,B, the percentage of $\mathrm{CD} 4^{+} \mathrm{CD} 25^{+} \mathrm{CD} 127^{\text {low }}$ and $\mathrm{CD}^{+} \mathrm{CD}_{2} 5^{+} \mathrm{FOXP}^{+}$was increased after expansion $(74.7 \pm 4.9$ vs $97.2 \pm 1.2$ and $75.3 \pm 5.1$ vs $97.3 \pm 0.5$, respectively). Noteworthy, in this study, we used a protocol mirroring the GMP Treg isolation showing the presence of a small fraction of cells negative for FOXP3 and positive for CD127. Similarly, we were able to detect FOXP3-positive cells in the Tconv fraction (Figures 2A,B).

The phenotypic analysis of freshly isolated Tregs, Tconv, and expanded Tregs showed an increased expression of functional markers such as CTLA-4, CD39, and GARP especially on expanded Tregs (Figures 2C,D). No statistically significant differences were found in the expression of HELIOS and TIGIT between freshly isolated and expanded Tregs. However, in comparison with Tconv, both freshly isolated and expanded Tregs expressed high level of these two markers (Figures 2C,D).

To further characterize the Tregs, we tested their suppressive ability. As expected, expanded Tregs showed the highest capacity to inhibit the proliferation of co-cultured CFSE-labeled effector cells when compared with freshly isolated Tregs and Tconv (Figure 2E).

Finally, to establish the cytokine profile produced by the different cell preparations, we activated freshly isolated Tregs, expanded Tregs, and Tconv in vitro for 3 days using anti-CD3/CD28 beads. Compared with freshly isolated Tregs and Tconv, expanded Tregs produced less IL-6, IL-17, and TNF- $\alpha$ (Figure 2F). Furthermore, both freshly isolated and expanded Tregs produced more IL-10 and TGF- $\beta$ compared with Tconv (Figure 2F). Although no statistically significant differences have been found, both freshly isolated and expanded Tregs tended to release more IL-13 than Tconv.

Overall, these results confirmed that expanded Tregs have an increased capacity to generate tolerance in comparison to freshly isolated Tregs and Tconv.

\section{Expanded Tregs Differentially Activate Monocytes Inducing a Unique Population}

To test the capacity of Tregs to activate/modulate $\mathrm{CD} 14^{+}$ monocytes, we co-cultured HLA-A2 ${ }^{-}$monocytes with HLA-A2 ${ }^{+}$ expanded Tregs, freshly isolated Tregs, and Tconv as detailed in Figure 1. We evaluated the impact of this interaction by measuring on monocytes the expression of CD80, CD86, CD14, CD206, CD163, CD40, and HLA-DR at day 0 and after 6 days of culture (Figure S2 in Supplementary Material; Figure 3A). Monocytes cocultured with expanded Tregs $\left(\mathrm{M}_{\mathrm{exp}}\right)$ expressed less HLA-DR both as percentage and MFI compared with monocytes co-cultured with Tconv $\left(\mathrm{M}_{25-}\right)$. Freshly isolated Tregs showed the capacity to reduce HLA-DR expression on monocytes $\left(\mathrm{M}_{25+}\right)$, but not to the same extent than expanded Tregs. Of note, no significant differences were found in the expression of HLA-DR between freshly isolated and cultured monocytes (Figure S2 in Supplementary Material; Figure 3A).

As Tregs have the potential to produce cytokines involved in the differentiation of $\mathrm{M} 2$ macrophages, we measured the expression of M2 specific markers such as CD206 and CD163. After 6 days of co-culture, the expression of these markers was increased in all the conditions when compared with the freshly isolated cells. However, monocytes co-cultured with either freshly isolated Tregs or expanded Tregs tended to upregulate the expression of $\mathrm{CD} 163$ more than $\mathrm{M}_{25-}$, while $\mathrm{M}_{\text {exp }}$ showed the highest levels (MFI) of CD206.

The analysis of the co-stimulatory molecules revealed a reduction of CD86 expression in $\mathrm{M}_{25+}, \mathrm{M}_{25-}$, and $\mathrm{M}_{\text {exp }}$ compared with freshly isolated monocytes. In detail, the comparison between $\mathrm{M}_{25}, \mathrm{M}_{25-}$, and $\mathrm{M}_{\text {exp }}$ showed that the highest expression of CD86 was on $\mathrm{M}_{25-}$ (Figure 3A). Conversely, CD40 was increased in all the conditions when compared with freshly isolated monocytes and $\mathrm{M}_{25}$ - showed the highest MFI (Figure $3 \mathrm{~A}$ ).

CD80 expression was not detected in all conditions before and after co-culture (data not shown). Of note, all monocytes from the co-cultures were positive for CD14, although in $\mathrm{M}_{25-} \mathrm{CD} 14$ MFI was significantly reduced compared with $\mathrm{M}_{25+}$ (Figure 3A).

We then performed an automated clustering method including $\mathrm{t}$-distributed stochastic neighbor embedding to use SNE visually (viSNE) as a mean of identifying different cell populations (41). Using the most representative markers commonly 
A

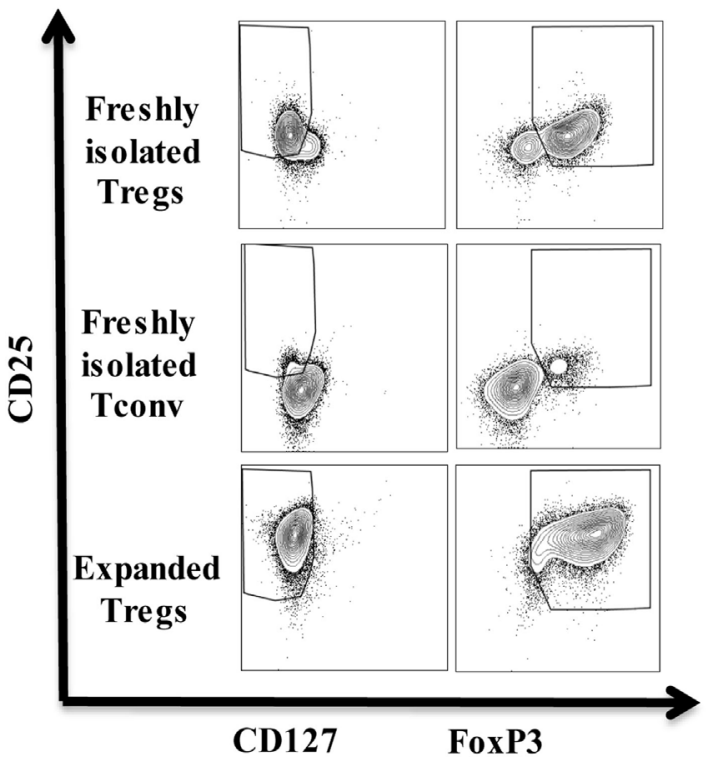

B
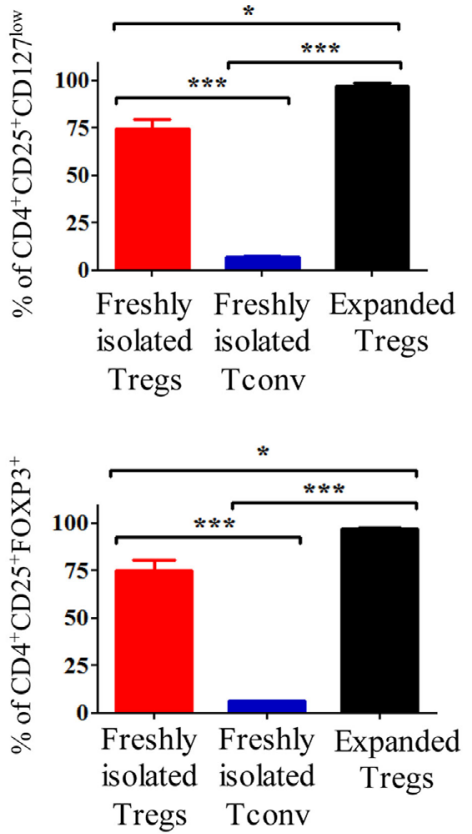

C
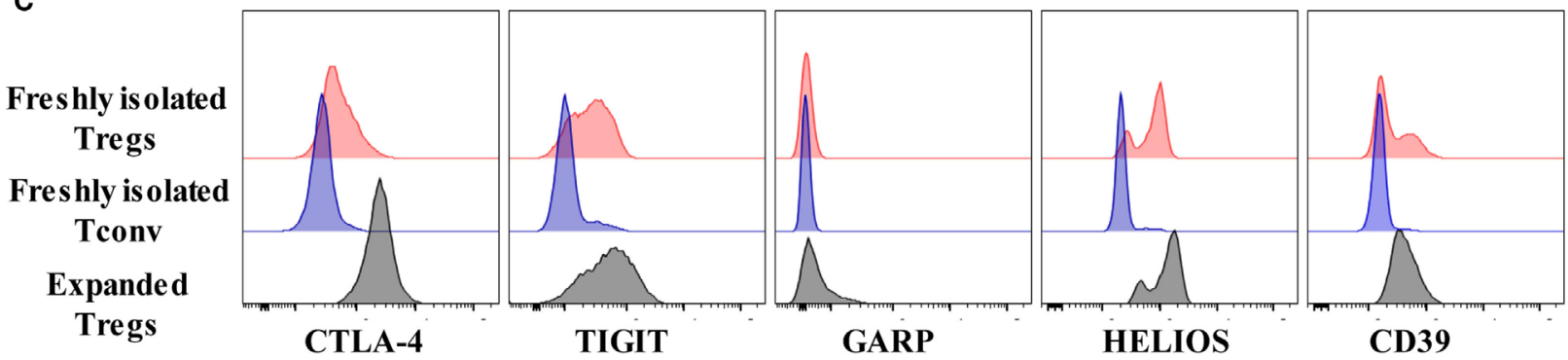

D
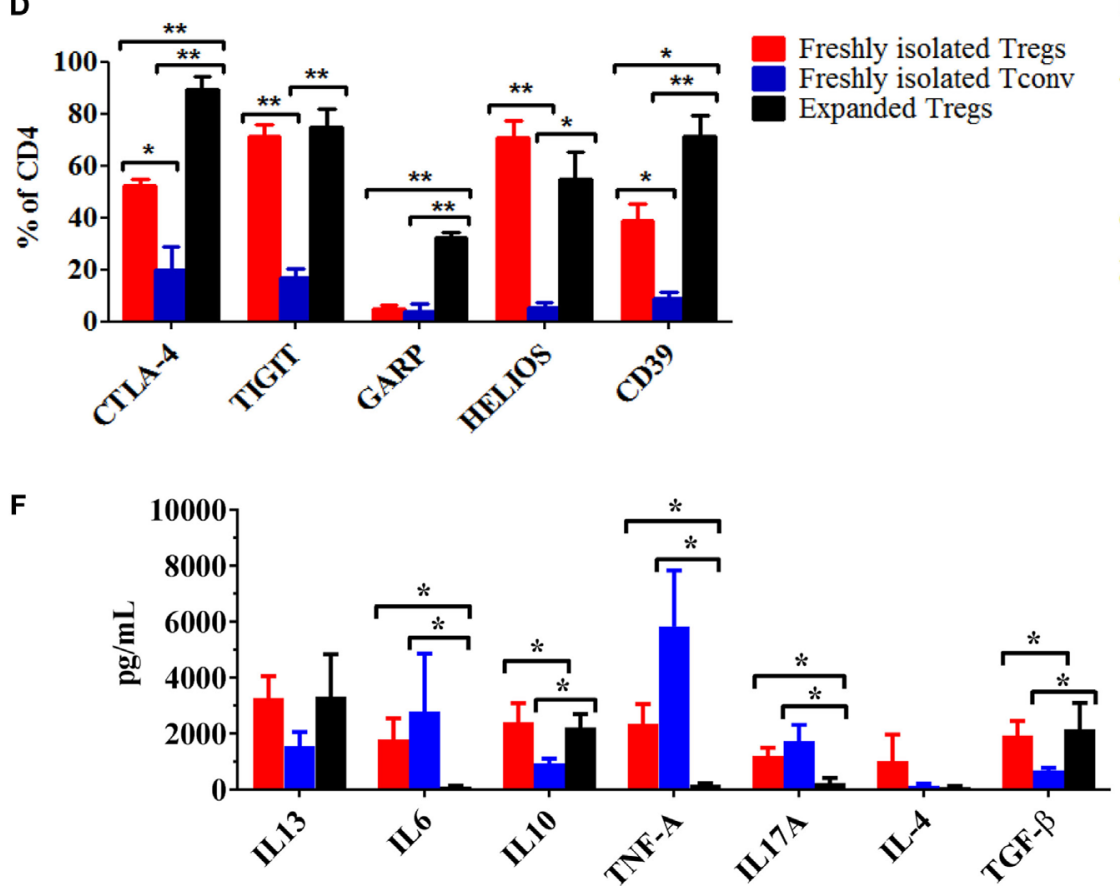

E

Freshly isolated Tregs Freshly isolated Tconv Expanded Tregs

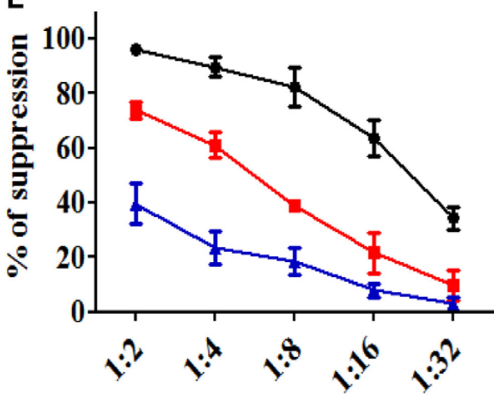

Freshly isolated Tregs

Freshly isolated Tconv

Expanded Tregs 
FIGURE 2 | Expansion of regulatory T cells (Tregs) using rapamycin increases their immunosuppressive capacity. (A) Representative dot plots showing the expression of CD25 vs FOXP3 and CD127 in expanded Tregs, freshly isolated Tregs and conventional T cell (Tconv). (B) Cumulative data of six independent experiments showing the percentages of $\mathrm{CD} 4^{+} \mathrm{CD} 25^{+} \mathrm{CD} 127^{\text {low }}$ and $\mathrm{CD} 4{ }^{+} \mathrm{CD} 25^{+} \mathrm{FOXP} 3^{+}$in expanded Tregs, freshly isolated Tregs and Tconv. Representative histogram (C) and cumulative data (D) of six independent experiments showing the expression of cytotoxic T-lymphocyte antigen-4 (CTLA-4), TIGIT, GARP, HELIOS, and CD39 in expanded Tregs, freshly isolated Tregs and Tconv. Data are expressed as percentage of expression of CD4+ cells. (E) Suppressive ability at different ratios of expanded Tregs, freshly isolated Tregs and Tconv vs third party Teff. Means of six independent experiments are expressed as percentage of inhibition of the Teff proliferation. (F) Cytokine production by expanded Tregs, freshly isolated Tregs and Tconv after 3 days stimulation with anti-CD3/CD28 beads (4:1 cells to beads ratio). Data are expressed as mean of six independent experiments. In all the experiments, data are presented as mean \pm SEM and analyzed using unpaired $t$-test with ${ }^{*} p<0.05,{ }^{* *} p<0.01$, and ${ }^{* \star *} p<0.001$.

used to discriminate M2 macrophages (CD86, CD14, CD206, CD163, and HLA-DR), we showed that $\mathrm{M}_{25+}, \mathrm{M}_{25-}$, and $\mathrm{M}_{\exp }$ clustered individually, confirming that expanded Tregs differentially activate monocytes compared with Tconv and freshly isolated Tregs (Figure 3B). In particular, we were able to detect a unique cluster (Figure 3B) which included CD14-positive cells expressing high levels of CD206, CD163 with low or no expression of CD86 and HLA-DR (Figure 3B). These data were confirmed by flow cytometry (Figures 3C,D) as the percentage of CD14 ${ }^{+}$ $\mathrm{CD} 206^{+} \mathrm{CD} 163^{+} \mathrm{CD} 86^{-}$cells was $5.15 \pm 1.26,3.07 \pm 0.7$, and $14 \pm 3.4$ in $\mathrm{M}_{25+}, \mathrm{M}_{25-}$, and $\mathrm{M}_{\exp }$ respectively. In line with viSNE analysis, the MFI for HLA-DR on $\mathrm{CD} 14^{+} \mathrm{CD} 206^{+} \mathrm{CD} 163^{+} \mathrm{CD} 86^{-}$ was significantly reduced when monocytes were co-cultured with expanded Tregs (Figure 3D). Similar to what we have shown by analyzing the monocyte populations as a whole, expanded Tregs were more powerful in reducing HLA-DR than freshly isolated Tregs.

In conclusion, we showed that the interaction of expanded Tregs with monocytes is more powerful in reducing co-stimulatory and MHC-class II molecules and in the upregulation of M2 macrophages specific markers.

\section{$M_{\text {exp }}$ Showed a Reduced Activation Status Compared With $\mathbf{M}_{25+}$ and $\mathbf{M}_{25-}$}

After activation, monocytes orchestrate both the initiation and resolution of inflammation mediating either pro-inflammatory or anti-inflammatory immune responses. For this reason, we investigated the activation status of $\mathrm{M}_{25+}, \mathrm{M}_{25-}$, and $\mathrm{M}_{\exp }$ cells. In monocytes, NF- $\kappa \mathrm{B}$ is an important transcriptional factor linked to the production of pro-inflammatory cytokines and cell surface receptors (42). Therefore, we evaluated the phosphorylation of NF- $\mathrm{KB}$ in sorted cells at the end of the co-culture as described in Figure 1. As shown in Figure 4A, we found a decreased activation of NF- $\mathrm{KB}$ in monocytes co-cultured with Tregs, and this effect was more pronounced in those cells cultured with expanded Tregs. Indeed, NF- $\kappa \mathrm{B}$ (p65) phosphorylation was significantly reduced in $\mathrm{M}_{\text {exp }}$ compared with $\mathrm{M}_{25-}$, although no statistical difference was observed between $\mathrm{M}_{\exp }$ and $\mathrm{M}_{25+}$ (Figure 4A).

Due to the different activation status of monocytes, we then evaluated their capacity to produce cytokines in response to LPS stimulation. As shown in Figure 4B, $M_{\exp }$ had a reduced capacity to secrete TNF- $\alpha$ compared with $\mathrm{M}_{25-}$, while IL- 6 and IL- 12 were reduced in both $\mathrm{M}_{25+}$ and $\mathrm{M}_{\exp }$ compared with $\mathrm{M}_{25-}$. Conversely, $\mathrm{M}_{\text {exp }}$ produced more IL-10 in comparison to either $\mathrm{M}_{25-}$ or $\mathrm{M}_{25+}$. Other cytokines such as IL-1 $\alpha$, IL-1 $\beta$, IL-18, and TLSP were not detected in any condition (data not shown). Similarly, no differences were found in the production of TGF- $\beta$ (Figure 4B).
As IL-10 controls genes implicated in the clearance of oxidative stress, we evaluated the expression of HO- 1 . This enzyme catalyzes heme degradation into carbon monoxide (CO), ferrous iron, and biliverdin. These cyto-protective molecules have antioxidant and anti-inflammatory properties, and they have been linked to both GvHD prevention (43) and induction of tolerance (26). As expected, HO-1 expression was upregulated in $\mathrm{M}_{\text {exp }}$ compared with $\mathrm{M}_{25+}$ and $\mathrm{M}_{25-}$ (Figure $4 \mathrm{C}$ ).

Here, we showed that expanded Tregs reduced monocytes activation and the release of pro-inflammatory cytokines. In addition, they increase the expression of molecules (IL-10 and HO-1) able to inhibit inflammation.

\section{$M_{\text {exp }}$ Reduced the Generation of IL-17- Producing Cells due to Their Lower CD86 Expression}

Although DCs are considered the main APCs able to activate and drive the differentiation of $\mathrm{T}$ helper cells, monocytes/macrophages can play a similar role (44). To test the capacity of $\mathrm{M}_{25+}$, $\mathrm{M}_{25-}$, and $\mathrm{M}_{\exp }$ monocytes to influence $\mathrm{T}$ helper differentiation/ proliferation, sorted cells (Figure S3 in Supplementary Material) were co-cultured with $\mathrm{CD} 4^{+} \mathrm{T}$ cells as described in Figure 1. After 6 days of co-culture, the percentages of IL-4, IL-17, IFN- $\gamma$, and IL-17/IFN- $\gamma$-producing cells were evaluated. As shown in Figures $\mathbf{5 A}, \mathbf{B}$, both freshly isolated and expanded Tregs reduced the percentage of IL-17 and IL-17/IFN- $\gamma$-producing cells compared with Tconv. Importantly, $\mathrm{M}_{\exp }$ were more powerful in reducing the percentages of IL-17-producing cells compared with $\mathrm{M}_{25+}(10.9 \pm 1.7$ vs $6.6 \pm 0.8 \%$, respectively). No statistically significant differences were found in the percentages of IL-4 and IFN- $\gamma$-producing cells. Finally, in none of the conditions, we could detect a stable induction of Tregs (data not shown).

The differentiation of IL-17-producing cells is mediated by IL-23, IL-1 $\beta$, TNF- $\alpha$, and IL-6 (45); however, this is not solely cytokine dependent (46). As $\mathrm{M}_{\exp }$ produced low levels of IL-6 and TNF- $\alpha$ with a reduced expression of co-stimulatory molecules, we co-cultured $\mathrm{M}_{25-}$ and $\mathrm{CD} 4^{+} \mathrm{T}$ cells together with factors inhibiting either cytokines or co-stimulatory molecules expression. Three different blocking monoclonal antibodies were used in this experiment: infliximab (anti-TNF- $\alpha$ ), tocilizumab (anti-IL-6 receptor), and abatacept (CTLA-4 fusion protein used to block CD80/CD86 co-stimulation). We found that the capacity of $\mathrm{M}_{25}$ to increase IL-17-producing cells was drastically reduced only in the presence of abatacept (Figures 5C,D). Of note, this was not due to cell death as the numbers at the end of the culture were comparable between $\mathrm{CD} 4^{+} \mathrm{T}$ cells co-cultured with $\mathrm{M}_{25-}$ alone or 


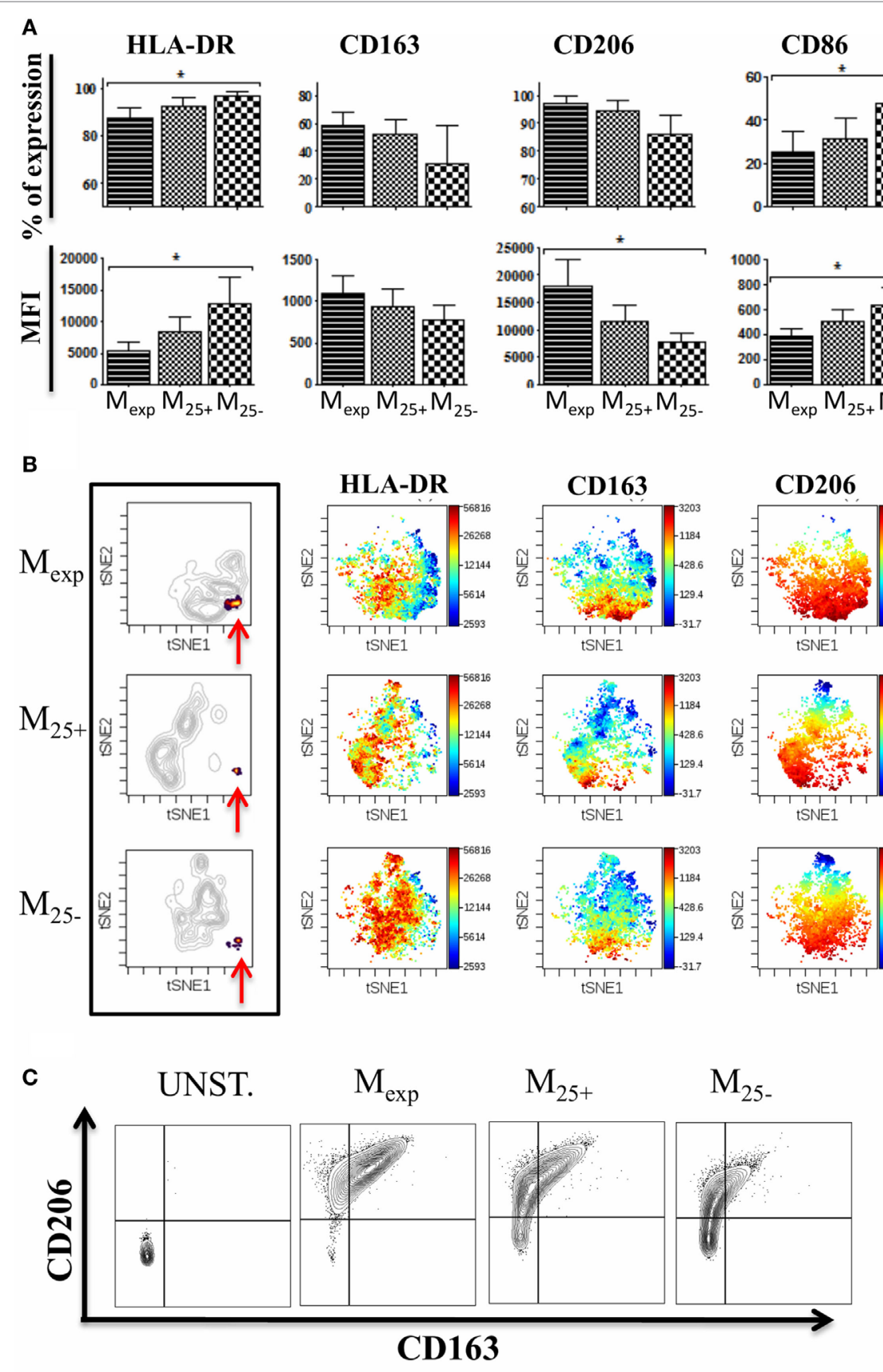

D
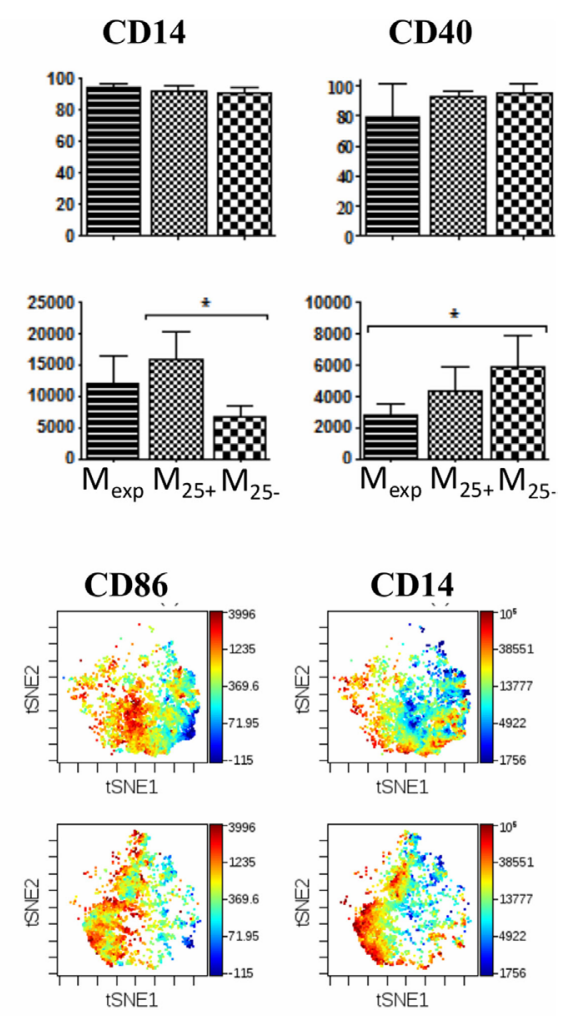

C
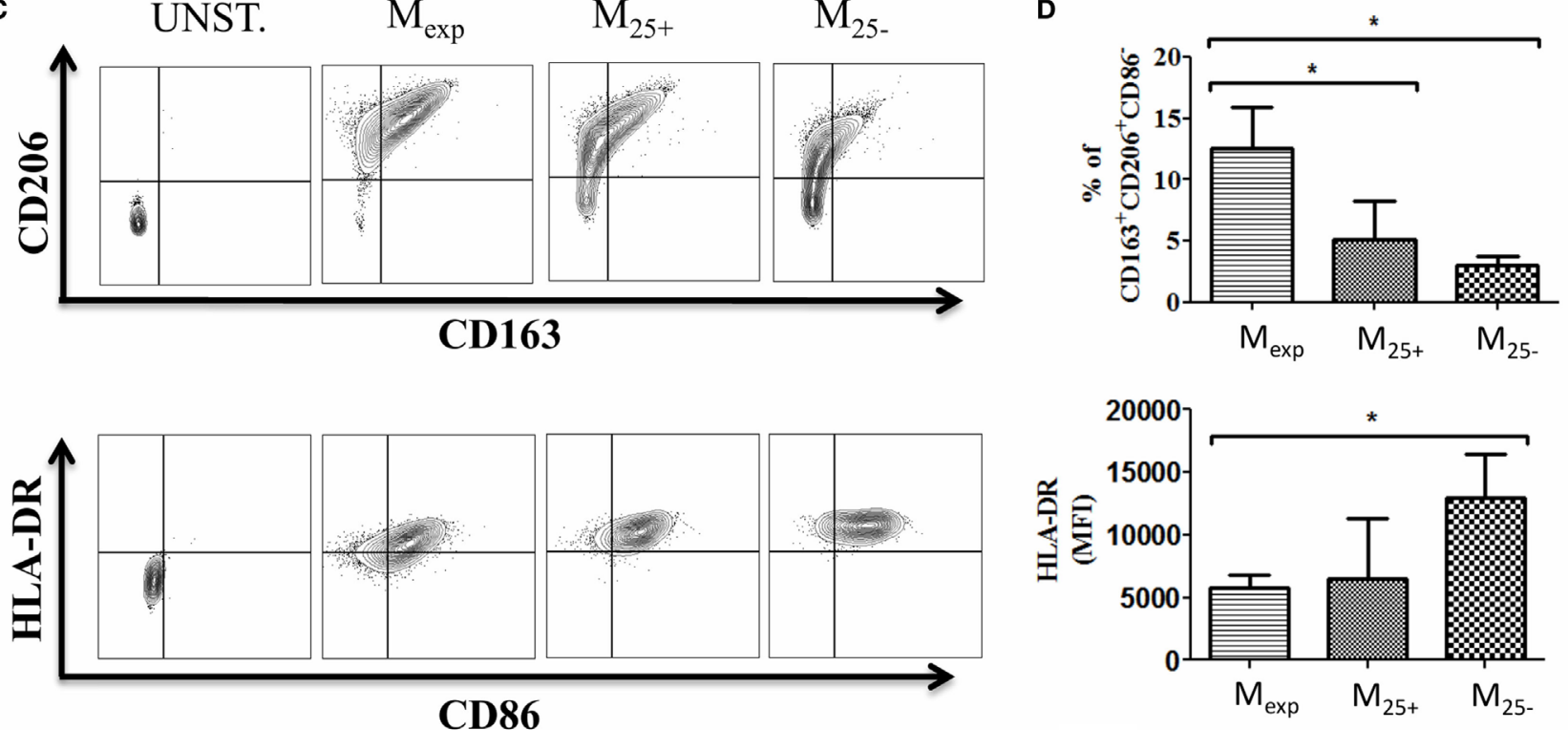

FIGURE 3 | Continued 
FIGURE 3 | Phenotype of monocytes after co-culture with T cells. (A) Expression of HLA-DR, CD86, CD14, CD206, CD163, and CD40 evaluated by flow cytometry on monocytes co-culture with expanded regulatory T cells (Tregs) ( $\left.\mathrm{M}_{\mathrm{exp}}\right)$, freshly isolated Tregs $\left(\mathrm{M}_{25+}\right)$, and freshly isolated conventional T cell ( $\left.\mathrm{M}_{25-}\right)$ for 6 days. Percentages of expression (upper panels) and MFI (lower panels) of 10 independent experiments. (B) Visualization of one representative automated clustering method including t-distributed stochastic neighbor embedding (t-SNE) highlighting the unique cluster (indicated by the red arrows) in $\mathrm{M}_{\text {exp }}$, $\mathrm{M}_{25+}$, and $\mathrm{M}_{25-}$ followed by the intensity of expression of HLA-DR, CD86, CD14, CD206, and CD163. (C) Representative plots showing CD206 and CD163 expression (upper panels) and HLA-DR plus CD86 on CD206+DC163+ cells (lower panel) in unstained control, $\mathrm{M}_{\text {exp }}, \mathrm{M}_{25+}$, and $\mathrm{M}_{25-}$ cells. (D) Cumulative data of six independent experiments showing the percentages of $\mathrm{CD} 14^{+} \mathrm{CD} 206^{+} \mathrm{CD} 163^{+} \mathrm{CD} 86^{-}$in $\mathrm{M}_{\exp }, \mathrm{M}_{25+}$, and $\mathrm{M}_{25-}$ (upper panel) and their HLA-DR expression (lower panel). In all the experiments, data, presented as mean \pm SEM, were analyzed using one-way ANOVA followed by Tukey with * $p<0.05$.

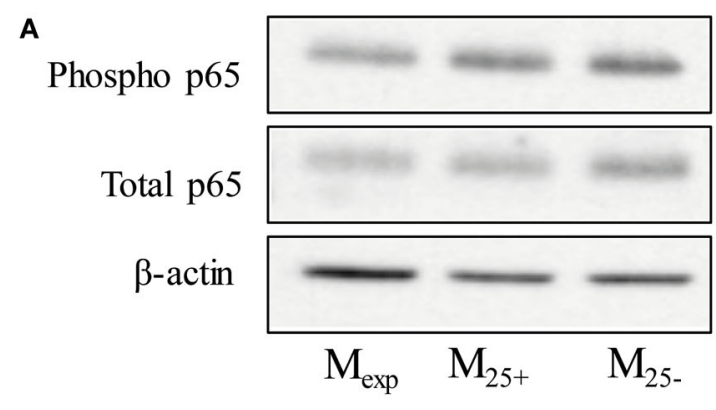

B TNF- $\alpha$

IL-6
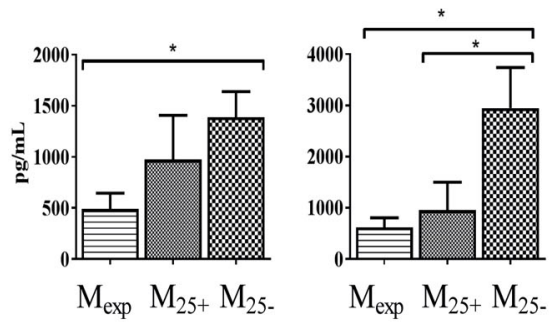

C

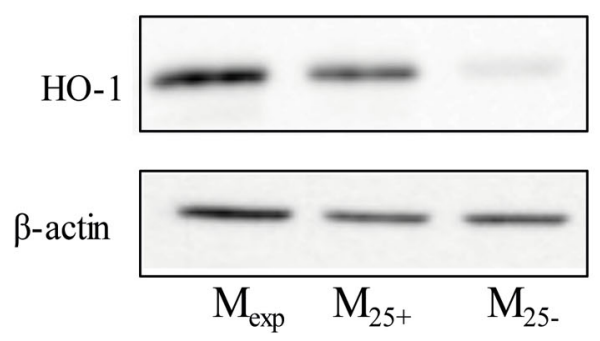

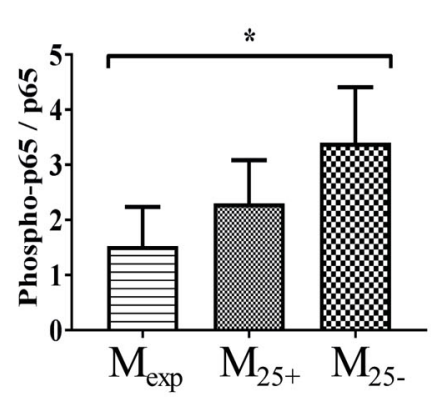

IL-12

TGF- $\beta$
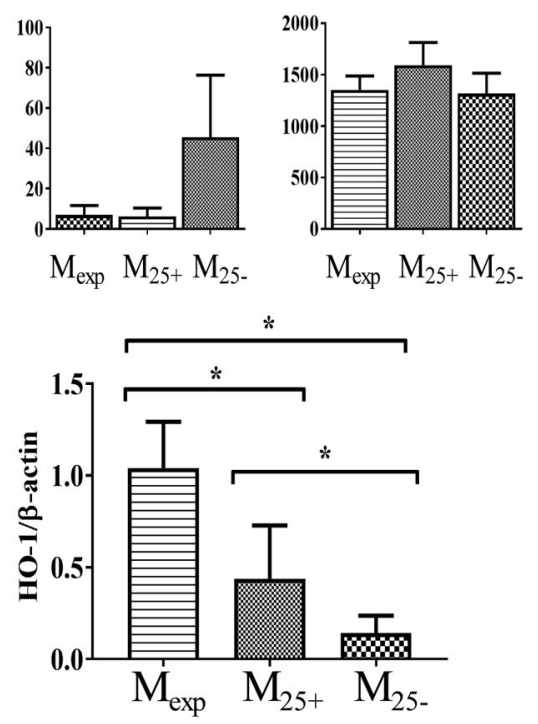

FIGURE 4 | $M_{\exp }$ showed a reduced activation status compared with $\mathrm{M}_{25+}$ and $\mathrm{M}_{25-}$. (A) Representative WB showing the expression of phosphorylated and total p65 and $\beta$-actin in $\mathrm{M}_{\mathrm{exp}}, \mathrm{M}_{25+}$, and $\mathrm{M}_{25-}$ (left panels); cumulative data of four independent experiments showing the ratio between phosphorylated and total p65 (right panel) in $\mathrm{M}_{\text {exp }}, \mathrm{M}_{25+}$, and $\mathrm{M}_{25-}$ cells. (B) Cytokine production of sorted $\mathrm{M}_{\exp }, \mathrm{M}_{25+}$, and $\mathrm{M}_{25-}$ after LPS stimulation (50 ng/mL) for 24 h. (C) Representative WB showing the expression of $\beta$-actin and heme oxygenase-1 (HO-1) in $M_{\exp }, \mathrm{M}_{25+}$, and $\mathrm{M}_{25-}$ (left panels); cumulative data of four independent experiments showing the ratio between $\mathrm{HO}-1$ and $\beta$-actin (right panel) in $\mathrm{M}_{\text {exp }}, \mathrm{M}_{25+}$, and $\mathrm{M}_{25-}$ cells. In all the experiments, data, presented as mean $\pm \mathrm{SEM}$, were analyzed using one-way ANOVA followed by Tukey with ${ }^{\star} p<0.05,{ }^{* *} p<0.01$. Full length-blots are presented in Figure S4 in Supplementary Material. The same representative $\beta$-actin blot is shown in panels $(\mathbf{A}, \mathbf{C})$.

in the presence of abatacept (Figure 5E). To further confirm the role of co-stimulation in the expansion of IL-17-producing T cells in our experimental condition, $\mathrm{CD}^{+} \mathrm{T}$ cells were stimulated with anti-CD3/CD28 beads in medium coming from $\mathrm{M}_{25}$ - culture (conditioned medium). No difference was observed between the two culture conditions confirming the need for cell:cell contact in Th-17 proliferation (Figure 5F).

Overall, our data suggest that $M_{\exp }$ had a reduced capacity to generate/expand IL-17- and IL-17/IFN- $\gamma$-producing T cells due mainly to their lower CD86 expression. 


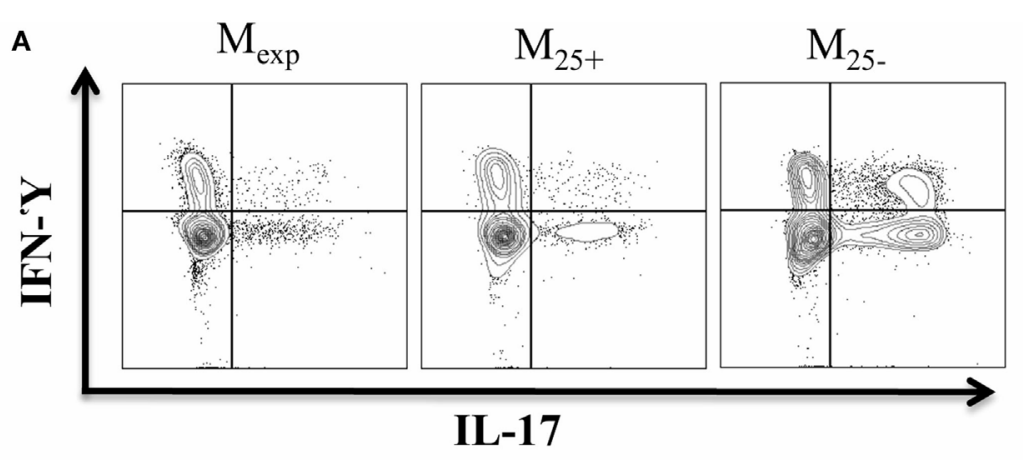

B
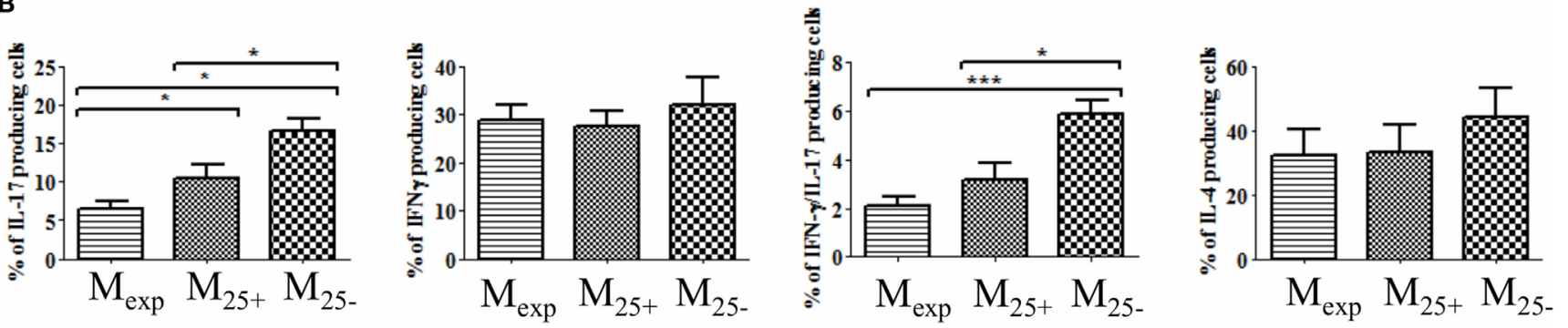

C
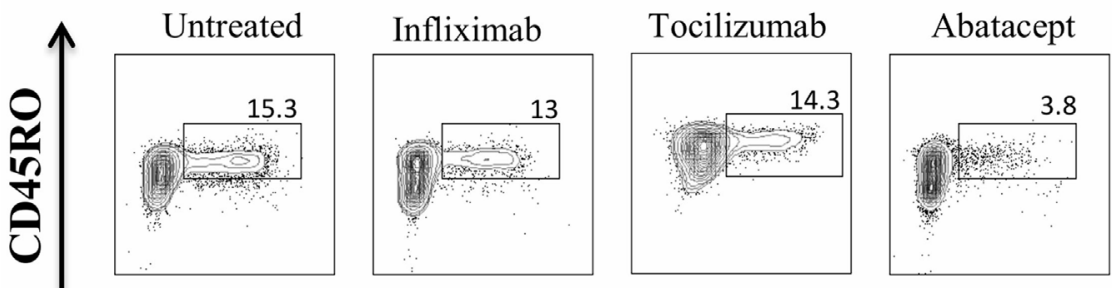

D

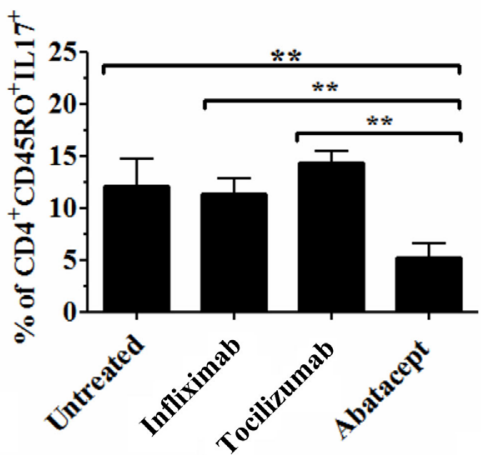

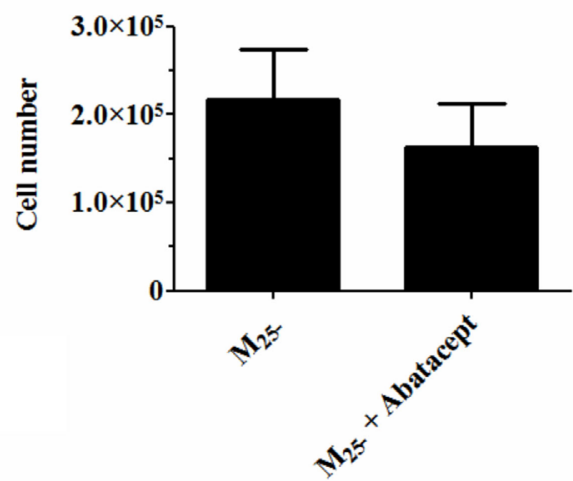

$\mathbf{F}$

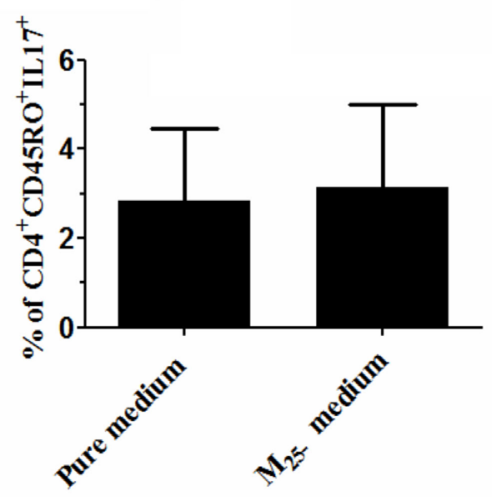

FIGURE 5 | Mexp reduced the generation of IL-17-producing cells due to their lower CD86 expression. (A) Representative plots showing the percentages of IL-17, $\mathrm{IL}-17 / \mathrm{IFN}-\gamma$, and IFN- $\gamma$-producing CD4+ cells after co-culture with $\mathrm{M}_{\mathrm{exo}}, \mathrm{M}_{25+}$, and $\mathrm{M}_{25-\text {. }}$ (B) Cumulative data of nine independent experiments showing the percentages of IL-17, IL-17/IFN- $\gamma$, and IFN- $\gamma$ and IL-4 producing CD4+ cells. Representative plots (C) and cumulative data (D) of four independent experiments showing the percentages of memory IL-17-producing CD4+ cells after co-culture with $\mathrm{M}_{25-}$ alone or in the presence of infliximab, tociluzmab, and abatacept. (E) Cell count of $\mathrm{CD}^{+}$cells $(n=4) \mathrm{co}$-cultured with $\mathrm{M}_{25}$ - alone or in the presence of Abatacept. $(\mathbf{F})$ Cumulative data of four independent experiments showing the percentages of memory IL-17-producing CD4+ stimulated with anti-CD3/28 beads in medium alone or $\mathrm{M}_{25-}$ conditioned medium. In all the experiments, data, presented as mean \pm SEM, were analyzed using one-way ANOVA followed by Tukey with ${ }^{*} p<0.05,{ }^{* *} p<0.01$. 


\section{DISCUSSION}

Over the past years, Tregs moved from promising cell candidates for tolerance induction to a therapeutic tool for the treatment of GvHD (47), autoimmune disorders (48), or to induce transplantation tolerance (49). Results from the first clinical trials showed that Tregs could be purified (47), expanded in GMP facilities (50), and re-infused in patients $(32,51)$. To date, the GMP immunomagnetic Treg isolation (CliniMACS) does not allow the purification of a highly pure FOXP $3^{+}$Treg product (47) as the cell fraction is contaminated with activated Tconv. To avoid the infusion of activated cells, we and others have developed Treg expansion protocols that include rapamycin $(36,52)$. These protocols have been demonstrated to be a successful approach for large-scale generation of functionally potent and phenotypically stable Tregs. Up to this stage, our group has positively completed two clinical trials investigating the safety of infusing ex vivo expanded Tregs in solid organ transplantation (the ONE Study and Thrill in kidney and liver transplantation, respectively). The outcomes of these trials are very promising; however, many questions remain unanswered, including which cells are targeted by Tregs in vivo.

Our expansion protocol allowed the proliferation of FOXP3 $3^{+}$ cells reducing contaminants from the freshly isolated fraction. Consistently, here we have shown that expanded Tregs do not produce TNF- $\alpha$, IL- 6 , and IL-17 and, at the same time, release high level of IL-10 and TGF- $\beta$. Expanded Tregs also express high level of functional markers like CTLA-4, GARP, and CD39. Furthermore, rapamycin expanded Tregs are more powerful than freshly isolated Tregs in driving monocytes differentiation toward alternatively activated macrophages (AAMs). In 2007, Tiemessen et al. described the ability of freshly isolated Tregs to drive monocytes toward AAMs (22). The authors showed that the co-culture of Tregs with monocytes upregulated M2-specific markers, reduced their NF- $\mathrm{kB}$ activation, and the release of proinflammatory cytokines. In line with these results, we found that expanded Tregs are more efficient than freshly isolated cells in doing so.

Tumor necrosis factor- $\alpha$ is crucial in all the phases of GvHD pathophysiology (53), and high concentrations of circulating TNF- $\alpha$ are considered as an immunological marker of graft rejection (54). CD14 ${ }^{+}$monocytes from healthy control cultured in the presence of TNF- $\alpha$ and GM-CSF differentiates into mature DCs or activated macrophages. Mature DCs expressed higher level of CD86 compared with those generated by GM-CSF and IL-4. As a consequence, these cells induced resting CD4 T cells to secrete IL-17. This evidence suggests that the priming of monocytes with TNF- $\alpha$ influences Th-17 responses induced by monocyte-derived mature DC (55). In our study, expanded Tregs decreased the expression of CD86 on monocytes during the co-culture. This effect might depend on the lack of TNF- $\alpha$ production, concomitant with the high level of IL-10 released by expanded Tregs. In addition, the presence of high level of CTLA-4 on these cells might also play a role in mediating the active removal of CD86 from cell surface. Importantly, the low levels of CD86 found in $\mathrm{M}_{\mathrm{exp}}$ are essential in reducing their capacity to induce IL-17-producing T cells, as demonstrated in the coculture of $\mathrm{M}_{25-}$ and $\mathrm{CD} 4^{+} \mathrm{T}$ cells where IL- 6 , TNF- $\alpha$, and the co-stimulatory molecules were blocked. Th- 17 have a detrimental effect in solid organ transplantation and $\operatorname{GvHD}(56,57)$. Recently, we published that spontaneously kidney-tolerant recipients exhibited reduced Th-17 responses compared with patients with chronic rejection and healthy individuals. These data suggested that defective pro-inflammatory Th-17 responses might contribute to the maintenance of a stable graft function in the absence of immunosuppressive agents (58). In addition, a recent study showed that monocytes isolated from patients with acute or chronic GvHD induced more Th-17 cells in vitro compared with monocytes from patients without GvHD and healthy donors (33). Altogether, these data confirmed that controlling IL-17producing $\mathrm{T}$ cells might be crucial for the induction of tolerance in transplantation and for the treatment of GvHD. Finally, TNF- $\alpha$ is also responsible for the activation of NF- $\mathrm{KB}$ (59). Therefore, the reduced production of TNF- $\alpha$ by expanded Tregs may explain the decreased phosphorylation of NF- $\mathrm{\kappa B}$ that, in turn, lead to a reduced capacity to produce pro-inflammatory cytokines in $\mathrm{M}_{\mathrm{exp}}$ compared with $\mathrm{M}_{25-}$.

In 2007, Tiemessen et al. hypothesized that the upregulation of CD206 by Tregs is contact dependent (22). In fact, when monocytes and Tregs were cultured together in the same well, but kept separated by a permeable support, monocytes were not able to upregulate CD206. However, in 2014, Fernando et al. (60) showed that during the in vitro differentiation of monocytes in M2a macrophages using IL-4 and IL-13, IL-6 enhanced the expression of CD206 in monocytes. In our culture conditions, expanded Tregs did not produce IL-6 compared with freshly isolated Tregs and Tconv reinforcing the idea that CD206 induction Treg-mediated might be controlled by a contact dependent mechanism. However, further investigations are needed to fully understand how $\mathrm{T}$ cells control the expression of CD206.

Both freshly isolated and expanded Tregs produced high level of IL-10 and TGF- $\beta$ compared with Tconv; these antiinflammatory cytokines have been linked with monocyte conversion to M2 type c macrophages (19). Our results showed consistently that both $\mathrm{M}_{25+}$ and $\mathrm{M}_{\text {exp }}$ had a reduced expression of CD86, CD40, and HLA-DR compared with $\mathrm{M}_{25}$, although statistically significant results were only obtained in the co-culture with expanded Tregs. This is probably due to the production of pro-inflammatory cytokines, such as TNF- $\alpha$ (released by the freshly isolated Treg fraction), which has been shown to induce CD40 and CD86 in monocytes/macrophages. Another protein upregulated in $\mathrm{M}_{\exp }$ compared with $\mathrm{M}_{25+}$ and $\mathrm{M}_{25-}$ was HO-1. This enzyme has an essential role in suppressing immune responses linked to inflammation (24), autoimmune diseases (25), and allograft rejection (26). Specifically, the pre-treatment of pancreatic allografts prior to transplantation with an $\mathrm{HO}-1$ inducer increased graft survival due to the reduction of pro-inflammatory and an increase in anti-inflammatory cytokines (61). HO-1 has a role in GvHD prevention as well; the high HO-1 expression in GvHD target organs may attenuate the acute phase of the disease through the regulation of the balance between Th-17 and Tregs (43). The role of HO-1 in macrophage polarization has been demonstrated (62), with M2 macrophages expressing high levels of this enzyme. HO- 1 expression can be regulated by IL-10 signaling and vice versa. Specifically, IL-10-mediated induction 
of HO-1 has been shown to require activation of STAT-3 and PI3K pathways in macrophage cell lines (62); subsequently, CO, the $\mathrm{HO}-1$ bio-product, increases IL-10 production. In our model, monocytes treated with Tregs, upregulated HO-1 expression. In particular, $\mathrm{M}_{\exp }$ were the cells with the highest HO-1 expression and the highest IL-10 production. This is in line with the positive feedback circuit between HO-1 and IL-10 reported in literature. These findings together with the reduced level of NF- $\kappa B$ phosphorylation might explain the observed reduced capacity of $\mathrm{M}_{\exp }$ to produce IL- 6 and TNF- $\alpha$.

Overall, we have shown the capacity of expanded Tregs to alternatively activate monocytes/macrophages by contact and nocontact dependent mechanisms. Importantly and relevant to the in vivo impact of Treg therapy, expanded Tregs induced a subset of monocytes/macrophages that are characterized by a unique signature. This might explain why we were able to detect the $\mathrm{CD} 14^{+} \mathrm{CD} 206^{+} \mathrm{CD} 163^{+} \mathrm{CD} 86^{-}$cell population with low HLA-DR expression in the $\mathrm{M}_{\exp }$ group.

In conclusion, the capacity of expanded Tregs to induce AAMs might shed light on the mechanisms adopted by expanded Tregs to favor tolerance in vivo. Our cell therapy protocol aims to modulate the ratio between activated effector cells and Tregs. Increasing the level of Tregs over the effector $\mathrm{T}$ cells might drive the monocytes differentiation toward a population producing low level of TNF- $\alpha$ and IL- 6 and high level of IL-10. Furthermore, the Treg-induced monocytes might be able to clear, by HO-1, the inflammation-mediated oxidative stress and contribute to reduce the infiltrating IL-17-producing cells responsible of graft rejection and GvHD progression. In conclusion, our in vitro model showed how expanded Tregs may favor the organ acceptance or reduce chronic inflammation. This might be exerted directly, inducing AAMs and/or indirectly through the reduction of IL-17-producing cells.

\section{ETHICS STATEMENT}

Peripheral blood mononuclear cells were obtained from anonymized human leukocyte cones supplied by the National

\section{REFERENCES}

1. Gupta S. Immune homeostasis: regulatory $\mathrm{T}$ cells (Treg) and molecules. J Clin Immunol (2008) 28:617-8. doi:10.1007/s10875-008-9259-3

2. Hori S, Nomura T, Sakaguchi S. Control of regulatory T cell development by the transcription factor Foxp3. Science (2003) 299:1057-61. doi:10.1126/ science. 1079490

3. Fontenot JD, Gavin MA, Rudensky AY. Foxp3 programs the development and function of CD4+CD25+ regulatory T cells. Nat Immunol (2003) 4:330-6. doi:10.1038/ni904

4. Toker A, Engelbert D, Garg G, Polansky JK, Floess S, Miyao T, et al. Active demethylation of the Foxp3 locus leads to the generation of stable regulatory T cells within the thymus. J Immunol (2013) 190:3180-8. doi:10.4049/ jimmunol.1203473

5. Yadav M, Stephan S, Bluestone JA. Peripherally induced Tregs - role in immune homeostasis and autoimmunity. Front Immunol (2013) 4:232. doi:10.3389/fimmu.2013.00232

6. Povoleri GA, Scottà C, Nova-Lamperti EA, John S, Lombardi G, Afzali B. Thymic versus induced regulatory $\mathrm{T}$ cells - who regulates the regulators? Front Immunol (2013) 4:169. doi:10.3389/fimmu.2013.00169

7. Wing JB, Sakaguchi S. Multiple Treg suppressive modules and their adaptability. Front Immunol (2012) 3:178. doi:10.3389/fimmu.2012.00178
Blood Transfusion Service (NHS blood and transplantation, Tooting, London, UK). Human studies were conducted in accordance with the Helsinki Declaration and approved by the Institutional Review Board of Guy's Hospital (Reference 09/ $\mathrm{H} 0707 / 86)$. Informed consent was obtained from all healthy donors prior to enrolment into the study.

\section{AUTHOR CONTRIBUTIONS}

MR conception design, collection and assembly data, data analysis and interpretation, and manuscript writing. GF, NT, RM, and EN-L collection and assembly data, data analysis, and interpretation. RL intellectual input and critical revision of the article. GL and CS conception and design, critical revision of the article for important intellectual contents.

\section{ACKNOWLEDGMENTS}

The authors want to acknowledge financial support from the Department of Health via the National Institute for Health Research (NIHR) comprehensive Biomedical Research Centre award to Guy's \& St. Thomas' NHS Foundation Trust in partnership with King's College London and King's College Hospital NHS Foundation Trust. The authors also acknowledge the support of the MRC Centre for Transplantation. The authors would like to thank Professor Leonie Taams for very helpful discussion.

\section{FUNDING}

This work was supported by grants from the British Heart Foundation (BHF; grant no. RG/13/12/30395 and grant no. TG/16/2/32657).

\section{SUPPLEMENTARY MATERIAL}

The Supplementary Material for this article can be found online at https://www.frontiersin.org/articles/10.3389/fimmu.2018.01625/ full\#supplementary-material.

8. Bai X, Shi H, Yang M, Wang Y, Sun Z, Xu S. Identification of key genes implicated in the suppressive function of human FOXP3+CD25+CD4+ regulatory $\mathrm{T}$ cells through the analysis of time-series data. Mol Med Rep (2018) 17:3647-57. doi:10.3892/mmr.2017.8366

9. Vignali D, Collison L, Workman C. How regulatory T cells work. Nat Rev Immunol (2008) 8:523-32. doi:10.1038/nri2343

10. Chaudhry A, Samstein RM, Treuting P, Liang Y, Pils MC, Heinrich J-MM, et al. Interleukin-10 signaling in regulatory $\mathrm{T}$ cells is required for suppression of Th17 cell-mediated inflammation. Immunity (2011) 34:566-78. doi:10.1016/ j.immuni.2011.03.018

11. Wan Y, Flavell R. "Yin-Yang" functions of transforming growth factor- $\beta$ and $\mathrm{T}$ regulatory cells in immune regulation. Immunol Rev (2007) 220:199-213. doi:10.1111/j.1600-065X.2007.00565.x

12. Mittal SK, Roche PA. Suppression of antigen presentation by IL-10. Curr Opin Immunol (2015) 34:22-7. doi:10.1016/j.coi.2014.12.009

13. Omosun Y, McKeithen D, Ryans K, Kibakaya C, Blas-Machado U, Li D, et al. Interleukin-10 modulates antigen presentation by dendritic cells through regulation of NLRP3 inflammasome assembly during Chlamydia infection. Infect Immun (2015) 83:4662-72. doi:10.1128/IAI.00993-15

14. Jenkins JK, Malyak M, Arend WP. The effects of interleukin-10 on interleukin-1 receptor antagonist and interleukin-1 beta production in human monocytes and neutrophils. Lymphokine Cytokine Res (1994) 13:47-54. 
15. Shin DI, Banning U, Kim YM, Verheyen J, Hannen M, Bönig H, et al. Interleukin 10 inhibits TNF-alpha production in human monocytes independently of interleukin 12 and interleukin 1 beta. Immunol Invest (1999) 28:165-75. doi:10.3109/08820139909061145

16. Arango Duque G, Descoteaux A. Macrophage cytokines: involvement in immunity and infectious diseases. Front Immunol (2014) 5:491. doi:10.3389/ fimmu.2014.00491

17. Parihar A, Eubank TD, Doseff AI. Monocytes and macrophages regulate immunity through dynamic networks of survival and cell death. JInnate Immun (2010) 2:204-15. doi:10.1159/000296507

18. Biswas SK, Mantovani A. Macrophage plasticity and interaction with lymphocyte subsets: cancer as a paradigm. Nat Immunol (2010) 11:889-96. doi:10.1038/ni.1937

19. Mia S, Warnecke A, Zhang X-M, Malmström V, Harris R. An optimized protocol for human M2 macrophages using M-CSF and IL-4/IL-10/TGF- $\beta$ yields a dominant immunosuppressive phenotype. Scand J Immunol (2014) 79:305-14. doi:10.1111/sji.12162

20. Lu J, Cao Q, Zheng D, Sun Y, Wang C, Yu X, et al. Discrete functions of M2a and $\mathrm{M} 2 \mathrm{c}$ macrophage subsets determine their relative efficacy in treating chronic kidney disease. Kidney Int (2013) 84:745-55. doi:10.1038/ki.2013.135

21. Rőszer T. Understanding the mysterious M2 macrophage through activation markers and effector mechanisms. Mediators Inflamm (2015) 2015:816460. doi:10.1155/2015/816460

22. Tiemessen $M$, Jagger $A$, Evans $H$, Herwijnen $M$, John $S$, Taams $L$. $\mathrm{CD} 4+\mathrm{CD} 25+$ Foxp3+ regulatory $\mathrm{T}$ cells induce alternative activation of human monocytes/macrophages. Proc Natl Acad Sci U S A (2007) 104:1944651. doi:10.1073/pnas.0706832104

23. Ricchetti GA, Williams LM, Foxwell BM. Heme oxygenase 1 expression induced by IL-10 requires STAT-3 and phosphoinositol-3 kinase and is inhibited by lipopolysaccharide. J Leukoc Biol (2004) 76:719-26. doi:10.1189/ jlb.0104046

24. Paine A, Eiz-Vesper B, Blasczyk R, Immenschuh S. Signaling to heme oxygenase- 1 and its anti-inflammatory therapeutic potential. Biochem Pharmacol (2010) 80:1895-903. doi:10.1016/j.bcp.2010.07.014

25. Chora AA, Fontoura P, Cunha A, Pais TF, Cardoso S, Ho PP, et al. Heme oxygenase- 1 and carbon monoxide suppress autoimmune neuroinflammation. J Clin Invest (2007) 117:438-47. doi:10.1172/JCI28844

26. Öllinger R, Pratschke J. Role of heme oxygenase-1 in transplantation. Transpl Int (2010) 23:1071-81. doi:10.1111/j.1432-2277.2010.01158.x

27. Walker LS. Treg and CTLA-4: two intertwining pathways to immune tolerance. J Autoimmun (2013) 45:49-57. doi:10.1016/j.jaut.2013.06.006

28. Qureshi OS, Zheng Y, Nakamura K, Attridge K, Manzotti C, Schmidt EM, et al. Trans-endocytosis of CD80 and CD86: a molecular basis for the cell-extrinsic function of CTLA-4. Science (2011) 332:600-3. doi:10.1126/science.1202947

29. Moini M, Schilsky ML, Tichy EM. Review on immunosuppression in liver transplantation. World J Hepatol (2015) 7:1355. doi:10.4254/wjh.v7.i10.1355

30. Garnett C, Apperley JF, Pavlu J. Treatment and management of graft-versushost disease: improving response and survival. Ther Adv Hematol (2013) 4:366-78. doi:10.1177/2040620713489842

31. Di Ianni M, Del Papa B, Cecchini D, Bonifacio E, Moretti L, Zei T, et al. Immunomagnetic isolation of CD4+CD25+FoxP3+ natural $\mathrm{T}$ regulatory lymphocytes for clinical applications. Clin Exp Immunol (2009) 156:246-53. doi:10.1111/j.1365-2249.2009.03901.x

32. Martelli MF, Di Ianni M, Ruggeri L, Falzetti F, Carotti A, Terenzi A, et al. HLA-haploidentical transplantation with regulatory and conventional T-cell adoptive immunotherapy prevents acute leukemia relapse. Blood (2014) 124:638-44. doi:10.1182/blood-2014-03-564401

33. Reinhardt K, Foell D, Vogl T, Mezger M, Wittkowski H, Fend F, et al. Monocyte-induced development of Th17 cells and the release of S100 proteins are involved in the pathogenesis of graft-versus-host disease. J Immunol (2014) 193:3355-65. doi:10.4049/jimmunol.1400983

34. Brunstein CG, Miller JS, McKenna DH, Hippen KL, DeFor TE, Sumstad D, et al. Umbilical cord blood-derived T regulatory cells to prevent GVHD: kinetics, toxicity profile, and clinical effect. Blood (2016) 127:1044-51. doi:10.1182/blood-2015-06-653667

35. Hippen KL, Merkel SC, Schirm DK, Sieben CM, Sumstad D, Kadidlo DM, et al. Massive ex vivo expansion of human natural regulatory T cells (T(regs)) with minimal loss of in vivo functional activity. Sci Transl Med (2011) 3:83ra41. doi:10.1126/scitranslmed.3001809
36. Scottà C, Esposito M, Fazekasova H, Fanelli G, Edozie FC, Ali N, et al. Differential effects of rapamycin and retinoic acid on expansion, stability and suppressive qualities of human CD4(+)CD25(+)FOXP3(+) T regulatory cell subpopulations. Haematologica (2013) 98:1291-9. doi:10.3324/haematol.2012.074088

37. Fraser H, Safinia N, Grageda N, Thirkell S, Lowe K, Fry LJ, et al. A rapamycin-based GMP-compatible process for the isolation and expansion of regulatory T cells for clinical trials. Mol Ther Methods Clin Dev (2018) 8:198-209. doi:10.1016/j.omtm.2018.01.006

38. van den Bosch T, Kannegieter N, Hesselink D, Baan C, Rowshani A. Targeting the monocyte-macrophage lineage in solid organ transplantation. Front Immunol (2017) 8:153. doi:10.3389/fimmu.2017.00153

39. Safinia N, Vaikunthanathan T, Fraser H, Thirkell S, Lowe K, Blackmore L, et al. Successful expansion of functional and stable regulatory T cells for immunotherapy in liver transplantation. Oncotarget (2016) 7:7563-77. doi:10.18632/ oncotarget.6927

40. Scottà C, Fanelli G, Hoong SJ, Romano M, Lamperti EN, Sukthankar M, et al. Impact of immunosuppressive drugs on the therapeutic efficacy of ex vivo expanded human regulatory T cells. Haematologica (2016) 101:91-100. doi:10.3324/haematol.2015.128934

41. Amir el- AD, Davis KL, Tadmor MD, Simonds EF, Levine JH, Bendall SC, et al. viSNE enables visualization of high dimensional single-cell data and reveals phenotypic heterogeneity of leukemia. Nat Biotechnol (2013) 31:545-52. doi:10.1038/nbt.2594

42. Liu T, Zhang L, Joo D, Sun S-C. NF- $\mathrm{BB}$ signaling in inflammation. Signal Transduction Targeted Ther (2017) 2:17023. doi:10.1038/sigtrans.2017.23

43. Yu M, Wang J, Fang Q, Liu P, Chen S, Zhe N, et al. High expression of heme oxygenase- 1 in target organs may attenuate acute graft-versus-host disease through regulation of immune balance of TH17/Treg. Transpl Immunol (2016) 37:10-7. doi:10.1016/j.trim.2016.05.002

44. Roberts CA, Dickinson AK, Taams LS. The interplay between monocytes/ macrophages and $\mathrm{CD} 4(+) \mathrm{T}$ cell subsets in rheumatoid arthritis. Front Immunol (2015) 6:571. doi:10.3389/fimmu.2015.00571

45. Yosef N, Shalek AK, Gaublomme JT, Jin H, Lee Y, Awasthi A, et al. Dynamic regulatory network controlling TH17 cell differentiation. Nature (2013) 496:461-8. doi:10.1038/nature11981

46. Evans HG, Suddason T, Jackson I, Taams LS, Lord GM. Optimal induction of $\mathrm{T}$ helper 17 cells in humans requires $\mathrm{T}$ cell receptor ligation in the context of toll-like receptor-activated monocytes. Proc Natl Acad Sci U S A (2007) 104:17034-9. doi:10.1073/pnas.0708426104

47. Di Ianni M, Del Papa B, Zei T, Iacucci Ostini R, Cecchini D, Cantelmi MG, et al. T regulatory cell separation for clinical application. Transfus Apher Sci (2012) 47:213-6. doi:10.1016/j.transci.2012.06.007

48. Bluestone JA, Buckner JH, Fitch M, Gitelman SE, Gupta S, Hellerstein MK, et al. Type 1 diabetes immunotherapy using polyclonal regulatory T cells. $S c i$ Transl Med (2015) 7:315ra189. doi:10.1126/scitranslmed.aad4134

49. Romano M, Tung SL, Smyth LA, Lombardi G. Treg therapy in transplantation: a general overview. Transpl Int (2017) 30:745-53. doi:10.1111/tri.12909

50. Putnam AL, Safinia N, Medvec A, Laszkowska M, Wray M, Mintz MA, et al. Clinical grade manufacturing of human alloantigen-reactive regulatory T cells for use in transplantation. Am J Transplant (2013) 13:3010-20. doi:10.1111/ ajt.12433

51. Theil A, Tuve S, Oelschlägel U, Maiwald A, Döhler D, Oßmann D, et al. Adoptive transfer of allogeneic regulatory $\mathrm{T}$ cells into patients with chronic graft-versus-host disease. Cytotherapy (2015) 17:473-86. doi:10.1016/j.jcyt. 2014.11.005

52. Golovina TN, Mikheeva T, Brusko TM, Blazar BR, Bluestone JA, Riley JL. Retinoic acid and rapamycin differentially affect and synergistically promote the ex vivo expansion of natural human T regulatory cells. PLoS One (2011) 6:e15868. doi:10.1371/journal.pone.0015868

53. Korngold R, Marini JC, de Baca ME, Murphy GF, Giles-Komar J. Role of tumor necrosis factor-alpha in graft-versus-host disease and graft-versus-leukemia responses. Biol Blood Marrow Transplant (2003) 9:292-303. doi:10.1016/ S1083-8791(03)00087-9

54. Budak D, Yilmaz VT, Akbas H, Suleymanlar G, Yucel G. Association between graft function and serum TNF- $\alpha$, TNFR1 and TNFR2 levels in patients with kidney transplantation. Ren Fail (2015) 37(5):871-6. doi:10.3109/08860 22X.2015.1015425

55. Iwamoto S, Iwai S, Tsujiyama K, Kurahashi C, Takeshita K, Naoe M, et al. TNFalpha drives human CD14+ monocytes to differentiate into CD70+ dendritic 
cells evoking Th1 and Th17 responses. JImmunol (2007) 179:1449-57. doi:10.4049/jimmunol.179.3.1449

56. Varelias A, Ormerod KL, Bunting MD, Koyama M, Gartlan KH, Kuns RD, et al. Acute graft-versus-host disease is regulated by an IL-17-sensitive microbiome. Blood (2017) 129:2172-85. doi:10.1182/blood-2016-08-732628

57. Heidt S, San D, Chadha R, Wood K. The impact of Th17 cells on transplant rejection and the induction of tolerance. Curr Opin Organ Transplant (2010) 15:456-61. doi:10.1097/MOT.0b013e32833b9bfb

58. Nova-Lamperti E, Romano M, Christakoudi S, Runglall M, McGregor R, Mobillo P, et al. Reduced TCR signaling contributes to impaired Th17 responses in tolerant kidney transplant recipients. Transplantation (2018) 102:e10-7. doi:10.1097/TP.0000000000001920

59. Chen C-C, Chou C-Y, Sun Y-T, Huang W-C. Tumor necrosis factor $\alpha$-induced activation of downstream NF- $\mathrm{KB}$ site of the promoter mediates epithelial ICAM-1 expression and monocyte adhesion. Cell Signal (2001) 13:543-53. doi:10.1016/s0898-6568(01)00171-1

60. Fernando MR, Reyes JL, Iannuzzi J, Leung G, McKay DM. The proinflammatory cytokine, interleukin-6, enhances the polarization of alternatively activated macrophages. PLoS One (2014) 9:e94188. doi:10.1371/journal. pone.0094188
61. Becker T, Zu Vilsendorf AM, Terbish T, Klempnauer J, Jörns A. Induction of heme oxygenase- 1 improves the survival of pancreas grafts by prevention of pancreatitis after transplantation. Transplantation (2007) 84:1644-55. doi:10.1097/01.tp.0000290233.81395.81

62. Naito Y, Takagi T, Higashimura Y. Heme oxygenase-1 and anti-inflammatory M2 macrophages. Arch Biochem Biophys (2014) 564:83-8. doi:10.1016/j.abb. 2014.09.005

Conflict of Interest Statement: The authors declare that the research was conducted in the absence of any commercial or financial relationships that could be construed as a potential conflict of interest.

Copyright (c) 2018 Romano, Fanelli, Tan, Nova-Lamperti, McGregor, Lechler, Lombardi and Scotta. This is an open-access article distributed under the terms of the Creative Commons Attribution License (CC BY). The use, distribution or reproduction in other forums is permitted, provided the original author(s) and the copyright owner(s) are credited and that the original publication in this journal is cited, in accordance with accepted academic practice. No use, distribution or reproduction is permitted which does not comply with these terms. 